\title{
DEVELOPMENT OF MATERIAL OPTIMIZATION TECHNOLOGY FOR SMALL STRUCTURES
}

\author{
IKUO TANABE \& PAULO DA SILVA \\ Department of Mechanical Engineering, Nagaoka University of Technology, Japan
}

\begin{abstract}
Many innovative products with multi-functions and of excellent quality are being manufactured. Although new ideas, concepts and innovations emerge, products with higher properties remain the market's favourite. Therefore, in this research, the material optimization technology for a small structure was developed and evaluated. Some small structures were desired for miniaturizing, weight and energy saving in the products. The concept of "material optimization" is a new and general idea. This material is of the composite type. The material optimization technology regarding Young's modulus, density, coefficient of linear expansion, specific heat and thermal conductivity were the main consideration of this research. The calculation models for the properties were discussed first and presented. The manufacturing method for a small structure with the desired properties was then developed. The small structure with the material optimization was manufactured and evaluated. It is concluded from the research that the technology was very effective and useful for the development of a new composite material with several hybrid properties.
\end{abstract}

Keywords: small structure, material optimization, new material, hybrid property, composite.

\section{INTRODUCTION}

In the 21st century, the demand for products with high quality [1], hybrid properties [2], multi-function [3] and considerable environment-friendliness [4] has been rapidly increasing. Here, several optimization technologies are currently being used to address these issues. Particularly, topology optimization technology is considered as useful in the manufacturing field due to the high quality, high reliability and safety that it offers. However, it has been observed that there is a lack of proper material optimization techniques in the technology development process. There are hundreds of materials used in the industrial field yet, surprisingly, the study on material property optimization for innovative development is very minimal.

Thus, previous research [5], through a developed software, defined a material optimization technology for innovation. The technology relied on a software that creates new materials with hybrid properties, a hybrid materials manufacturing method, and an algorithm for material optimization. The aforementioned software can effectively calculate up to five desired material properties that are requested (i.e. Young's modulus, density, coefficient of linear expansion, specific heat and thermal conductivity). In addition, the algorithm for material optimization was defined through FEM inverse analysis. The material optimization technology was then evaluated with a simple experiment. In this regard, it was thought that material optimization technologies were highly relevant to explore due to the design and manufacturing implications of having a customized material.

In the present research, the material optimization technology for small structures was developed and evaluated. A new manufacturing process was developed for a small structure with a new composite. The previous software which could effectively calculate up to five desired material properties that are requested at once (i.e. Young's modulus, density, coefficient of linear expansion, specific heat and thermal conductivity) was evaluated for a small structure in several experiments. A material optimization algorithm using FEM inverse analysis and the previous software [5] was considered. 


\section{PROPERTIES CALCULATION MODELS FOR NEW COMPOSITE MATERIALS}

In this section, a previously developed software and the several equations are quoted [5]-[8]. There are density, thermal conductivity, specific heat, coefficient of linear expansion and Young's modulus among properties considered in the calculation models. Their calculation accuracies are shown in [9].

\section{PROPOSED MANUFACTURING PROCESS FOR SMALL STRUCTURES WITH A NEW COMPOSITE}

In a similar way, the defined proposed manufacturing method for the designed materials using the aforementioned equations in a software (which defined two scenarios (1) Selecting materials and calculating appropiate ratios to achieve intended effects; (2) Calculating the properties generated with these ratios and materials) and its method that was used in the previous research are applied in this study. Consequently, a review of the process was deemed appropiate. For the aforementioned software, a solid body uniformity was assumed for each calculation model but conventional manufacturing of composite or composites (mixing) yields an heterogeneous mix which as a result would be considered as a material defect [9], [10]. Thus, the proposed new manufacturing process was meant to achieve high quality by avoiding this issue. The new manufacturing procedure is shown in Fig. 1. Here, a bonding material (e.g. epoxy resin), a fine aggregate, a middle aggregate and a coarse aggregate were firstly put into an under small mould and filled up to about 6 vl.\%, 10 vl.\%, 24 vl.\% and $60 \mathrm{vl} . \%$ respectively as revealed in Fig. 1(a). The bond and the aggregates in the mould were mannually mixed. Then they were continuously mixed by an ultrasonic scaler with $2-3 \mu \mathrm{m}$ amplitude and 28-30 kHz vibration frequency in Fig. 1(b) (see Fig. 2(a)).

This process was performed for removing the unnecessary air in the mixing composite, and was continued for a few minutes till all air bublles were fully transfered to the surface of the composite. Lastly, an upper small mould was put on the upper surface of the composite, and the upper mould was knocked by the ultrasonic scaler in Fig. 1(c) (see Fig. 2(b)). The upper mould was gradually sank till the composite reached the most high density condition. In the final condition, the coarse aggregate becomes about $60 \mathrm{vl} . \%$ in the mould, the available air given space for the middle aggregate was about $40 \mathrm{vl} \% \%$ relative to the coarse aggregate. Thus, given that the middle aggregate filled up about $60 \mathrm{vl} \%$ of the total space, $40 \mathrm{vl} . \%$ would mean that the aggregate filled about $24 \mathrm{vl} . \%(=0.4 \times 0.6)$. Consequently, the coarse and

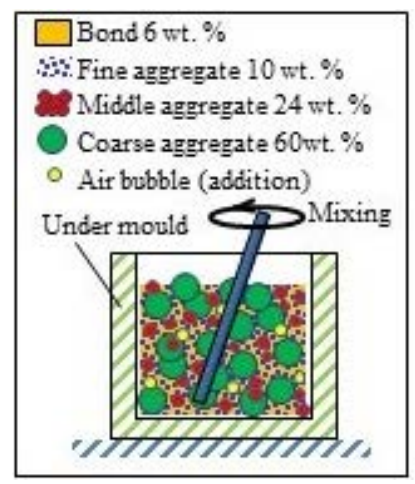

(a)



(b)

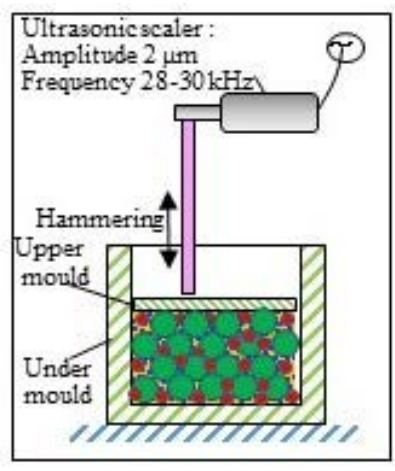

(c)

Figure 1: Manufacturing process for small structure with new composite. (a) Mixing process; (b) Removing air process; and (c) Hammering process. 


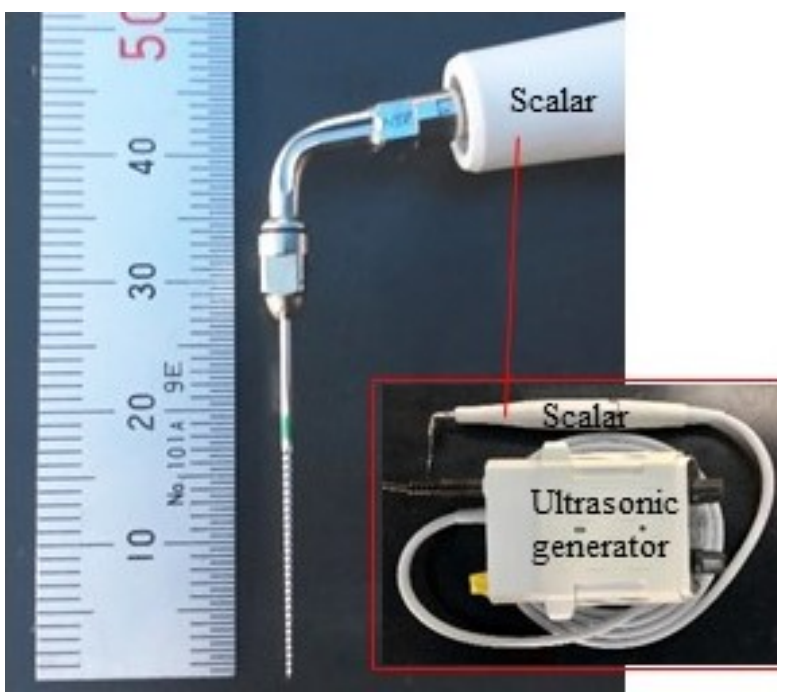

(a)

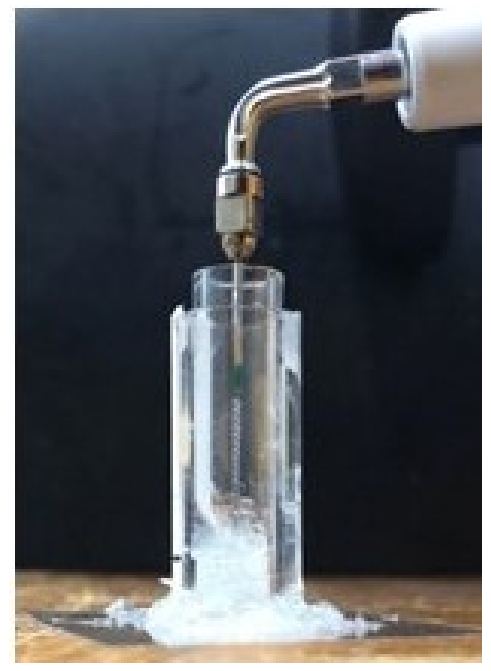

(b)

Figure 2: Schematic view for small structure with new composite in manufacturing process. (a) Ultrasonic scalar for removing air and hammering; and (b) Schematic view for removing air.

the middle aggregates uniformly filled up 84 vl.\% (=60 vl.\%+24 vl.\%). In addition, fine aggregate was also poured into the mix to fill the gaps between the middle aggregates. It was thought that this aggregate would have filled up to $10 \mathrm{vl} . \%(=(100-60-24) \times 0.6)$. As a result, all aggregates uniformly filled around $94 \mathrm{vl} . \%(=60 \mathrm{vl} . \%+24 \mathrm{vl} . \%+10 \mathrm{vl} . \%)$. It must be considered that space was meant to be filled by the aggregates in a rhombic display and, thus, the mixture becomes a mortar structure. Bonding materials (e.g. epoxy resin) were meant to be poured from upper surface over all aggregates. Upon solidification of the bonding materials, the generated composite material was removed from the mould. Here, the component distribution was similar to that of the calculation model. For these, the size of the middle aggregate was restricted to be less than one seventh of the coarse aggregate. Meanwhile, the relationship between the fine and the middle aggregates is also the same. Therefore when the mould volume $V_{\mathrm{m}}$ is decided, the volumes and the weights regarding the coarse, the middle and the fine aggregates and the bond can very easily be calculated, and the good timing for agreement between the under and upper moulds can also be estimated. This timing is the limit of the upper mould sinking (Fig. 1(c)) and the highest density condition.

Working times for manufacturing the small sturcture with the new composite are shown in Fig. 3. The small structure was the right cylinder with $5 \mathrm{~mm}$ diameter and $10 \mathrm{~mm}$ length. It consists of coase aggregate (Glass: $0.7 \mathrm{~mm}$ diameter and $60 \mathrm{wt} . \%$ ), middle aggregate (Glass: $0.08 \mathrm{~mm}$ diameter and $24 \mathrm{wt} . \%$ ), fine aggregate (Carbon: $0.005 \mathrm{~mm}$ diameter and 10 wt.\%) and bond (Epoxy resin: 6 wt.\%) (see Table 1, Sample No. 1). The working times for the three processes; mixing, air removing and hammering are $0.5 \mathrm{~min}, 2.1 \mathrm{~min}$ and 1.3 min respectively. Working times for the samples No. 2 and No. 3 in Table 1 were similar to the sample No. 1 . The working times is very effective in the industrial field. 


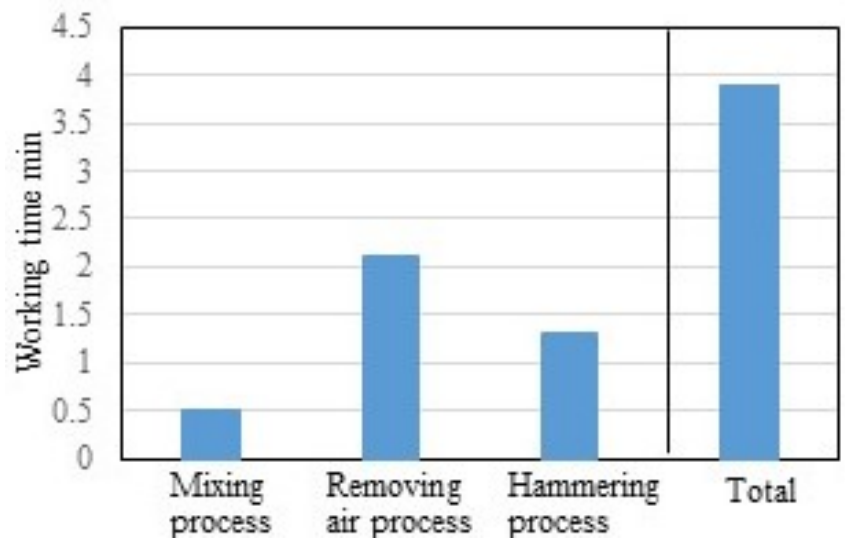

Figure 3: Working times for small structures with new composite in the manufacturing process.

Table 1: The specification of ultrasonic scaler, used materials and its properties for the test.

\begin{tabular}{|c|c|c|c|c|c|c|c|c|c|}
\hline \multicolumn{10}{|c|}{ Specification of the used devices for the small structure with the new composite } \\
\hline \multirow{4}{*}{\multicolumn{2}{|c|}{$\begin{array}{l}\text { Ultrasonic } \\
\text { scaler }\end{array}$}} & \multirow{4}{*}{\multicolumn{3}{|c|}{$\begin{array}{c}\text { Varios } 370 \\
\text { (NSK-Nakanishi JAPAN) }\end{array}$}} & \multirow{4}{*}{\multicolumn{2}{|c|}{$\begin{array}{l}\text { Power } \\
\text { Amplitude } \\
\text { Vibration frequency } \\
\text { Size }\end{array}$}} & \multicolumn{3}{|c|}{$11 \mathrm{~W}$} \\
\hline & & & & & & & \multicolumn{3}{|c|}{$2-3 \mu \mathrm{m}$} \\
\hline & & & & & & & \multicolumn{3}{|c|}{$28-32 \mathrm{kHz}$} \\
\hline & & & & & & & \multicolumn{3}{|c|}{ W80×D115×H32 mm } \\
\hline \multicolumn{10}{|c|}{ The used material, wt.\%, size for test pieces } \\
\hline $\begin{array}{l}\text { Sample } \\
\text { No. }\end{array}$ & \multicolumn{2}{|c|}{$\begin{array}{c}\text { Coarse } \\
\text { aggregate }\end{array}$} & $\begin{array}{c}\text { Middle } \\
\text { aggregate }\end{array}$ & $\begin{array}{c}\text { Fine } \\
\text { aggregate }\end{array}$ & Bond & & \multicolumn{3}{|c|}{ Calculated properties } \\
\hline \multirow{5}{*}{ No. 1} & \multirow{5}{*}{\multicolumn{2}{|c|}{$\begin{array}{l}\text { Glass } \\
0.7 \mathrm{~mm} \\
60 \mathrm{vl} . \%\end{array}$}} & \multirow{5}{*}{$\begin{array}{l}\text { Glass } \\
0.08 \mathrm{~mm} \\
24 \mathrm{vl} . \%\end{array}$} & \multirow{5}{*}{$\begin{array}{l}\text { Carbon } \\
0.005 \mathrm{~mm} \\
10 \mathrm{vl} . \%\end{array}$} & \multirow{5}{*}{$\begin{array}{l}\text { Epoxy } \\
\text { resin } \\
6 \mathrm{vl} \%\end{array}$} & \multicolumn{3}{|c|}{ Young's modulus GPa } & 41 \\
\hline & & & & & & \multicolumn{3}{|c|}{ Density $\mathrm{kg} / \mathrm{m}^{3}$} & 2210 \\
\hline & & & & & & \multicolumn{3}{|c|}{ Thermal conductivity W/(mK) } & 0.61 \\
\hline & & & & & & \multicolumn{3}{|c|}{ Coefficient of linear expansion $\mathrm{K}^{-1}$} & $10 \times 10^{-6}$ \\
\hline & & & & & & \multicolumn{3}{|c|}{ Specific heat kJ/(kg $\cdot \mathrm{K})$} & 0.84 \\
\hline \multirow{5}{*}{ No. 2} & \multirow{5}{*}{\multicolumn{2}{|c|}{$\begin{array}{c}\text { Alumina } \\
0.7 \mathrm{~mm} \\
60 \mathrm{vl} . \%\end{array}$}} & \multirow{5}{*}{$\begin{array}{l}\text { Alumina } \\
0.08 \mathrm{~mm} \\
24 \mathrm{vl} . \%\end{array}$} & \multirow{5}{*}{$\begin{array}{l}\text { Silicon } \\
\text { nitride } \\
0.01 \mathrm{~mm} \\
10 \mathrm{vl} . \%\end{array}$} & \multirow{5}{*}{$\begin{array}{l}\text { Epoxy } \\
\text { resin } \\
6 \mathrm{vl} \% \%\end{array}$} & \multicolumn{3}{|c|}{ Young's modulus GPa } & 136 \\
\hline & & & & & & \multicolumn{3}{|c|}{ Density $\mathrm{kg} / \mathrm{m}^{3}$} & 3540 \\
\hline & & & & & & \multicolumn{3}{|c|}{ Thermal conductivity $\mathrm{W} /(\mathrm{mK})$} & 20 \\
\hline & & & & & & Coeffici & of linear expansion & & $10 \times 10^{-6}$ \\
\hline & & & & & & Specific & at $\mathrm{kJ} /(\mathrm{kg} \cdot \mathrm{K})$ & & 0.98 \\
\hline & & & & & & Young's & odulus GPa & & 79 \\
\hline & & & Alumina & Carbon & Epoxy & Density & $\mathrm{m}^{3}$ & & 5770 \\
\hline No. 3 & 0.7 & & $0.08 \mathrm{~mm}$ & $0.005 \mathrm{~mm}$ & resin & Thermal & nductivity W/(mK) & & 5.9 \\
\hline & & & 24 vl.\% & 10 vl.\% & $6 \mathrm{vl} . \%$ & Coeffici & of linear expansion & & $12.1 \times 10^{-6}$ \\
\hline & & & & & & Specific & at $\mathrm{kJ} /(\mathrm{kg} \cdot \mathrm{K})$ & & 0.58 \\
\hline & & Prope & the & materials & III SIIIC & tructure $\mathrm{v}$ & the new composite & & \\
\hline Material & & $\begin{array}{r}\mathrm{Y} \\
\bmod \end{array}$ & $\begin{array}{l}\text { oung's } \\
\text { ulus GPa }\end{array}$ & \begin{tabular}{l|l} 
Density \\
$\mathrm{kg} / \mathrm{m}^{3}$
\end{tabular} & $\begin{array}{r}\text { Thermal con } \\
\mathrm{W} /(\mathrm{m}\end{array}$ & luctivity & $\begin{array}{l}\text { Coefficient of } \\
\text { linear expansion } \\
1 / \mathrm{K} \\
\end{array}$ & & $\begin{array}{l}\text { ecific heat } \\
\mathrm{J} /(\mathrm{kg} \cdot \mathrm{K})\end{array}$ \\
\hline Steel & & & 210 & 7800 & 30 & & $12 \times 10^{-6}$ & & 0.46 \\
\hline Glass & & & 69 & 2460 & 0.75 & & $9.0 \times 10^{-6}$ & & 0.84 \\
\hline Alumina & & & 340 & 3920 & 34.7 & & $10 \times 10^{-6}$ & & 1.1 \\
\hline Silicon ni & ride & & 300 & 3200 & 17 & & $3 \times 10^{-6}$ & & 0.7 \\
\hline Carbon & & & 8.9 & 740 & 0.12 & & $2.1 \times 10^{-6}$ & & 1.3 \\
\hline Epoxy res & & & 2.6 & 1200 & 0.4 & & $96 \times 10^{-6}$ & & 0.6 \\
\hline
\end{tabular}


Specification of the ultrasonic scaler used in the manufacturing process, the materials for the test pieces used in Section 4 and each material property for the all new composites are shown in Table 1 . The ultrasonic scaler used in the manufacturing process is a device for a dental clinic. Three small structures with new composite; samples No. 1, No. 2 and No. 3 were manufactured for evaluation purposes in Section 4. At that time, several properties for samples No. 1, No. 2 and No. 3 were also calculated by the calculation models in Section 2. All samples are manufactured by the manufacturing process described in Section 3.

In this research, the smallest size for the small structure (right cylinder) was $5 \mathrm{~mm}$ diameter because of the suitable sizes for coarse, middle and fine aggregates. It is no problem for the manufacturing process (Section 3) to produce a required small size for the structure.

\section{EVALUATION OF DEVELOPED CALCULATION MODELS AND MANUFACTURING PROCESS}

The calculation models for Young's modulus, density, coefficient of linear expansion, thermal conductivity and specific heat in Section 2 were evaluated. As both the density and the specific heat of the composite can easily and exactly be calculated by the composite ratio of the used materials, the evaluation of these properties was not performed in this section.

\subsection{Evaluation for Young's modulus}

A schematic view of the experimental set-up regarding Young's modulus for the new composites is shown in Fig. 4(a). Samples No. 1, No. 2 and No. 3 in Table 1 were used for this Young's modulus evaluation. Test piece sizes are $5 \mathrm{~mm}$ diameter and $20 \mathrm{~mm}$ height. (1) The test piece is put up in the guide pipe with $6 \mathrm{~mm}$ inner diameter. (2) $100 \mathrm{~N}$ of compression force is loaded on the test piece. (3) The displacement $\ell$ of the top of the test piece is measured by a CCD camera. (4) The Young's modulus $E$ can be calculated by knowing the cross section area A and height $h$ of the test piece, the displacement $\ell$ and the compression load $P$ $(E=P \div A \div \ell \times h)$. The results for evaluation of the Young's modulus and calculated value $E_{\text {cal }}$ and the experimental value $E_{\text {ex }}$ are shown in Fig. 4(b). When the experimental value $E_{\text {ex }}$

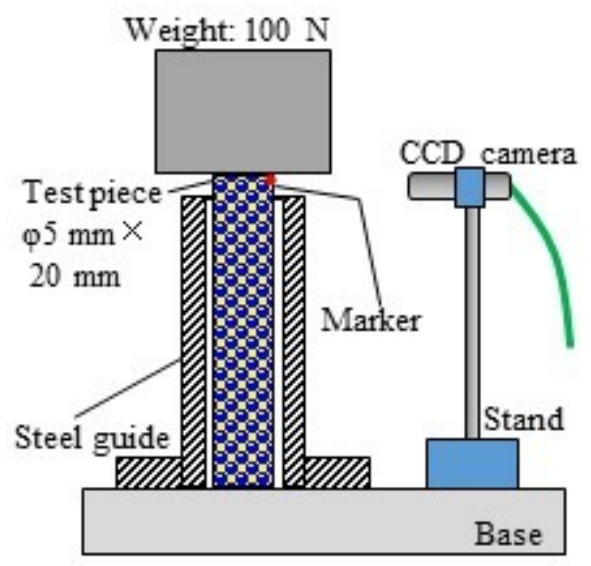

(a)



(b)

Figure 4: Evaluation of Young's modulus. (a) Schematic view of experimental set-up; and (b) Experiment results of Young's modulus. 
is compared with the calculated value $E_{\text {cal }}$, the experimental error for Young's modulus is around $-3.6 \%$ to $-4.8 \%\left(=\left(E_{\mathrm{ex}}-E_{\mathrm{cal}}\right) \div E_{\mathrm{cal}} \times 100\right)$. The reasons were that the new composite was not perfectly in the highest density condition and the residual air in the new composite had very small influence on the Young's modulus.

\subsection{Evaluation for coefficient of linear expansion}

A schematic view of the experimental set-up regarding the coefficient of linear expansion for the new composites is shown in Fig. 5(a). Samples No. 1, No. 2 and No. 3 in Table 1 were used for this coefficient of linear expansion evaluation. Test piece sizes are $5 \mathrm{~mm}$ in diameter and $20 \mathrm{~mm}$ in height $h$. (1) The side of the test piece is insulated for heat transfer by styrene foam with $10 \mathrm{~mm}$ thickness. (2) The test piece with styrene foam is inserted and kept for very long time (about 24 hours) in the homoisothermal vessel at $100^{\circ} \mathrm{C}$. (3) Then the test piece is put on an air conditioning room at $20^{\circ} \mathrm{C} \pm 1^{\circ} \mathrm{C}$ the displacement $\ell$ of the top of the test piece is measured by a CCD camera till the test piece temperature is $20^{\circ} \mathrm{C}$. (4) The coefficient of linear expansion $\alpha$ can calculated by the heaght $h$ and temperature diffrence $\Delta T$ of the test piece and the displacement $\ell(\alpha=\ell \div \Delta T \div h)$. Thermal behaviour of the test piece in the initial stage which is from the removal of test piece in the homoisothermal vessel to start the measurement was complemented by using the relationship between the test piece temperature and the test piece displacement. It was confirmed that the coefficient of linear expansion for steel could be measured by using this method. The result for evaluation of the coefficient of linear expansion is shown in Fig. 5(b), which also reveals the calculated value $\alpha_{\text {cal }}$ and the experimental value $\alpha_{\mathrm{ex}}$. When the experimental value $\alpha_{\mathrm{ex}}$ is compared with the calculated value $\alpha_{\mathrm{c}}$, the experimental error for coefficient of linear expansion is around $+1.8 \%-+1.2 \%$ $\left(=\left(\alpha_{\text {ex }}-\alpha_{\text {cal }}\right) \div \alpha_{\text {cal }} \times 100\right)$. The reasons are that the new composite is not perfectly in the highest density condition and the residual air in the new composite has small influence on the coefficient of linear expansion because of small Young's modulus.

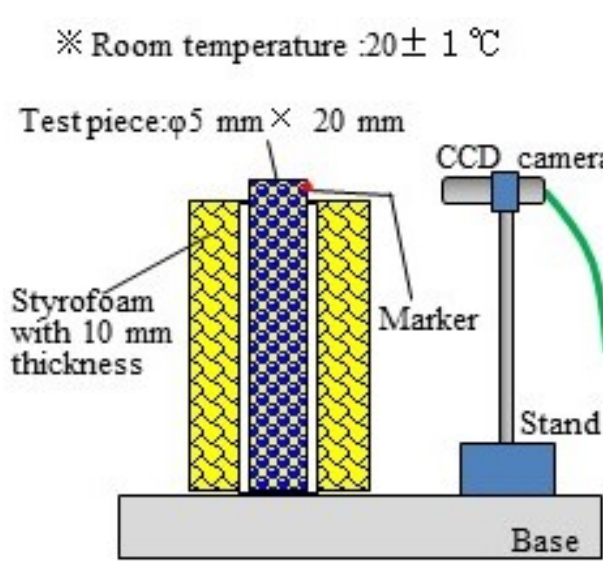

(a)

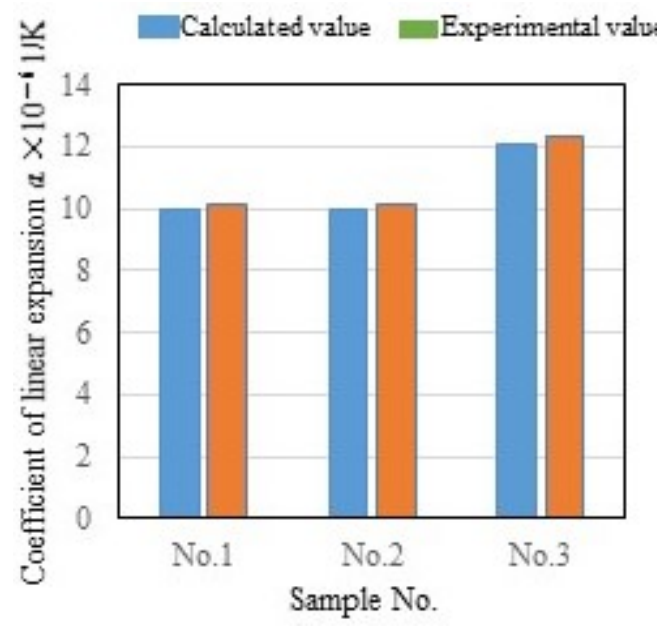

(b)

Figure 5: Evaluation of coefficient of linear expansion. (a) Schematic view of experimental set-up; and (b) Experiment results of Young's modulus. 


\subsection{Evaluation for thermal conductivity}

The schematic view of thermal conductivity experimental set-up for the new composites is shown in Fig. 6(a). Sample No. 1, Sample No. 2 and Sample No. 3 in Table 1 were used for the evaluation. Test piece sizes are $5 \mathrm{~mm}$ in diameter and $10 \mathrm{~mm}$ in height $h$. (1) The two test pieces are put up on both sides of the ceramics heater $(5 \mathrm{~W}, 5 \mathrm{~mm}$ diameter and $1.5 \mathrm{~mm}$ thickness). (2) The side of the test piece is insulated for heat transfer by styrene foam with $10 \mathrm{~mm}$ thickness. (3) The top $T_{\mathrm{T}}$ and the bottom $T_{\mathrm{B}}$ temperatures of the test piece at the steady state condition are measured by the thermo-couples with $\mathrm{T}$ type in the air conditioning room at $20^{\circ} \mathrm{C}$. (4) The thermal conductivity $\lambda$ can be calculated by knowing the top $T_{\mathrm{T}}$ and the bottom $T_{\mathrm{B}}$ temperatures of the test piece at steady state, cross section area $A$ and height $h$ of the test piece, the displacement $\ell$ and the heat generation $W$ compression load $\mathrm{L}$ ( $\lambda=W \times\left(T_{\mathrm{T}}\right.$ $\left.-T_{\mathrm{B}}\right) \div 2 \div A \div h$ ). The result from the evaluation of the thermal conductivity is shown in Fig. 6(b). The calculated value $\lambda_{\text {cal }}$ and the experimental value $\lambda_{\text {ex }}$ are shown in this figure. When the experimental value $\lambda_{\text {ex }}$ is compared with the calculated value $\lambda_{\text {cal }}$, the experimental error for thermal conductivity is around $-2.9 \%$ to $-3.8 \%\left(=\left(\lambda_{\text {ex }}-\lambda_{\text {cal }}\right) \div \lambda_{\text {cal }} \times 100\right)$. The reasons are that the new composite is not perfectly in the highest density condition and the residual air in the new composite has small influence on the thermal conductivity.

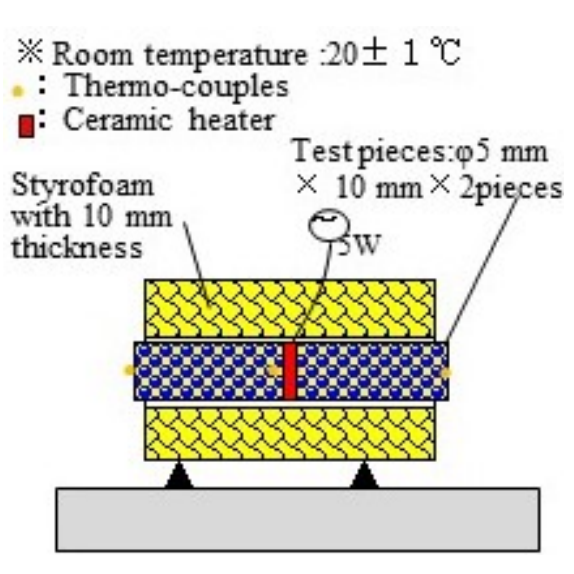

(a)



(b)

Figure 6: Evaluation of thermal conductivity. (a) Schematic view of experimental set-up; and (b) Experiment results of Young's modulus.

The calculation accuracy was evaluated in the section. The calculations for coefficient of linear expansion was accurate to around $+1.8 \%-+1.2 \%$ but the Young's modulus and thermal conductivity were around $-2.9 \%$ to $-4.8 \%$. This was thought to be because of air formation in the composite material and the FEM simulations were modified accordingly; as a result, the software calculation accuracy for the Young's modulus and thermal conductivity reached an error down to a $\pm 2 \%$ each. The developed calculation models and manufacturing process were evaluated in several cases with the generation of new composites with hybrid properties. 


\section{MATERIAL OPTIMIZATION ALGORITHM USING FEM INVERSE ANALYSIS}

Material optimization software using inverse analysis has already being developed in our research [9]. And in this section, the proposed software was used for the small structure. An algorithm of the material optimization using inverse analysis of the FEM was developed as depicted. At first, an innovative product with the most suitable function was decided by using a marketing data. The most suitable properties for the innovative product were calculated by both the inverse analysis of the FEM simulation and the method of successive substitution in the personal computer. The FEM simulations features are static analysis, thermal analysis and vibration analysis which are outlined in Table 2. It also shows the relationship between the different simulation features and the necessary properties for each analysis. The necessary materials and the composite ratio for the new materials with the most suitable properties were finally calculated by our software. Then the new composite material with the most suitable property was manufactured by the procedure described in Section 3.

Table 2: Various properties for the input data in certain FEM simulations.

\begin{tabular}{|c|c|c|c|}
\hline \multicolumn{2}{|c|}{ Types of FEM simulation } & Boundary conditions & Input data for FEM \\
\hline \multicolumn{2}{|c|}{ Static analysis } & Fix condition & $\begin{array}{c}\text { Shape and size } \\
\text { Material properties (Young's } \\
\text { modulus and Poisson's ratio) }\end{array}$ \\
\hline \multirow{2}{*}{$\begin{array}{c}\text { Thermal } \\
\text { analysis }\end{array}$} & Steady state & $\begin{array}{c}\text { Heat transfer } \\
\text { coefficient }\end{array}$ & $\begin{array}{c}\text { Shape and size } \\
\text { Material properties (Thermal } \\
\text { conductivity) }\end{array}$ \\
\cline { 2 - 5 } & Non-steady state & $\begin{array}{c}\text { Heat transfer } \\
\text { coefficient }\end{array}$ & $\begin{array}{c}\text { Shaterial properties(Density, } \\
\text { specific heat and thermal } \\
\text { conductivity) }\end{array}$ \\
\hline $\begin{array}{c}\text { Vibration } \\
\text { analysis }\end{array}$ & Free vibration & $\begin{array}{c}\text { Shape and size } \\
\text { Fix condition }\end{array}$ & $\begin{array}{c}\text { Material properties(Young's } \\
\text { modulus and density) }\end{array}$ \\
\cline { 2 - 5 } & Forced vibration & $\begin{array}{c}\text { Shape and size } \\
\text { damping ratio }\end{array}$ & $\begin{array}{c}\text { Material properties(Young's } \\
\text { modulus and density) }\end{array}$ \\
\hline
\end{tabular}

Note: At thermal deformation analysis, both Static and Thermal analysis are used, and coefficient of linear expansion is also used for input data. Poisson's ratio is always 0.3 .

\section{CONCLUSIONS}

It is concluded from the results that:

1. The expanded proposed software was able to calculate Young's modulus, density, coefficient of linear expansion, specific heat and thermal conductivity for several material samples as previously proposed. Through the selection of adequate materials and the calculation of their ratios, it was possible to achieve specific desired properties in a new composite material.

2. The calculation of resultant properties was carried out given that the component materials and their ratios in a composite material are known. A small structure with material optimization was manufactured and evaluated. It is concluded from the results that the technology was very effective and useful for the development of a new composite material with several hybrid properties. 


\section{REFERENCES}

[1] Moriwaki, T., Shamoto, E. \& Tokunaga, T., Thermal deformation of an ultra-precision machine tool due to environmental temperature change. Transactions of the Japan Society of Mechanical Engineers, Transaction of JSME, Series C, 63(615), pp. 40254030, 1997. (In Japanese.)

[2] Nakajima, H., Lotus-type porous metals. Bulletin of The Iron and Steel Institute of Japan, 6(9), pp. 701-707, 2001. (In Japanese.)

[3] Kobayashi, T., Matsubayashi, T. \& Shibata, K., On the improvement of the damping capacity of a steel structure by overlaying with fiber-reinforced plastics. Transaction of JSME, Series C, 58(554), pp. 3096-3101, 1992. (In Japanese.)

[4] Okada, M., Hosokawa, A., Asakawa, N., Fujita, Y. \& Ueda, T., Influence of minimum quantity lubrication on tool temperature in end milling of difficult-to-cut materials having low thermal conductivity. Transaction of JSME, Series C, 78(792), pp. 30933103, 2012. (In Japanese.)

[5] Tanabe, I., Development of software for the creation of new material with hybrid properties. WIT Transactions on Engineering Sciences, vol. 116, WIT Press: Southampton and Boston, pp. 139-147, 2017.

[6] Russell, H.W., Principles of heat flow in porous insulators. J. Am. Ceram. Society, 18, pp. 1-5, 1956.

[7] Tanabe, I., Development of technology for creating composite materials of machine tool. Int. J. of Automation Technology, 9(6), pp. 714-719, 2015.

[8] Tanabe, I. \& Silva, P.D., Development of material optimization technology for innovation. WIT Transactions on the Built Environment, vol. 175, WIT Press: Southampton and Boston, pp. 101-109, 2018.

[9] Tanabe, I., Takiguchi, S. \& Iyama, T., Development of software for creating new materials with hybrid properties. Transaction of JSME, Series C, 78(786), pp. 595604, 2012. (In Japanese.)

[10] Tanabe, I., Takada, K. \& Nakamura, A., Thermal and mechanical characteristics of epoxy resin composite used in machine tool structures. Transaction of JSME, Series C, 56(525), pp. 1314-1321, 1990. (In Japanese.) 